\title{
Temporal Lobe Epilepsy - Pathophysiology and Mechanisms
}

\author{
Leong Tung Ong \\ Department of Medicine, Faculty of Medicine, University of Malaya, Kuala Lumpur, Malaysia
}

$\mathrm{T}$ emporal lobe epilepsy (TLE) is a disorder of the nervous system due to unprovoked seizures originating from the temporal lobe. The main cause of TLE is neuronal hyperexcitability due to the presence of pathological changes in the temporal lobe of the brain such as neuronal loss, mutation, granule cell dispersion and malformations of cortical development. This editorial discusses important aspects of the pathogenesis underlying TLE.

\section{Keywords}

Temporal lobe epilepsy, seizures, pathophysiology

Disclosure: Leong Tung Ong has nothing to disclose in relation to this article.

Review Process: Double-blind peer review.

Compliance with Ethics: This article is an opinion piece and does not report on new clinical data, or any studies with human or animal subjects performed by the author

Authorship: The named author meets the International Committee of Medical Journal Editors (ICMJE) criteria for authorship of this manuscript, takes responsibility for the integrity of the work as a whole, and has given final approval for the version to be published.

Access: This article is freely accessible at

touchNEUROLOGY.com. (C) Touch Medical Media 2020

Received: 15 November 2019

Accepted: 2 December 2019

Published Online: 17 January 2020

Citation: European Neurological Review.

2019;14(2):66-7

Corresponding Author: Leong Tung Ong, Department of Medicine, Faculty of Medicine, University of Malaya, 50603 Kuala Lumpur, Malaysia. E: leotungong@gmail.com

Support: No funding was received in the publication of this article.
Seizure is a paroxysmal event caused by the excessive, hypersynchronous discharge of neurons in the brain, which causes alteration in neurologic function. ' Seizures can occur when there is a distortion between the normal balance of excitation and inhibition in the brain. The factors that cause this alteration in the balance of excitation and inhibition can be genetic or acquired. ${ }^{\text {T }}$ The definition of epilepsy, based on the International League Against Epilepsy (ILAE), is a disease of the brain causing at least two unprovoked or reflex seizures occurring more than 24 hours apart or, if after one seizure, the risk of recurrence is 'high' $(>60 \%)^{2}$

Temporal lobe epilepsy (TLE) is a disorder of the nervous system which describes unprovoked seizures originating from the temporal lobe, and is further classified by the ILAE, as mesial TLE (MTLE) and lateral TLE (LTLE). ${ }^{3.4}$ MTLE is the more common form of TLE, accounting for two-thirds of cases, ${ }^{3}$ and within this classification, hippocampal sclerosis (HS) is a common pathology. ${ }^{4,5}$ The ILAE classification has several advantages in the diagnosis of TLE: it is based on typical clinical features, it recognises the localisation of seizures (e.g., those originating from the amygdalo-hippocampal area and seizures coming from the lateral temporal lobe), and the addition of MTLE with HS to the classification. ${ }^{2}$ There are, however, some limitations to the ILAE classification, which include the exclusion of diagnostic modalities such as, magnetic resonance imaging and electroencephalography. ${ }^{6}$

The ILAE defines HS as severe segmental loss of pyramidal neurons in the CA1 region, and less prominent neuronal loss can be seen in the areas CA3 and CA4. ${ }^{7.8}$ Experimental models show that activation of $\mathrm{N}$-methyl-d-aspartate (NMDA) receptors can produce neuronal loss in TLE. ${ }^{9}$ Electrical stimulation of the afferent pathway to the hippocampus of healthy animal brains replicates the cell loss that is associated with TLE, and has shown that repetitive seizures cause a persistent loss of recurrent inhibition and irreversibly damaged adjacent interneurons. ${ }^{10}$ Gamma-aminobutyric acid (GABA) is the main inhibitory neurotransmitter that inhibits neuronal firing by activating two different classes of receptors, $\mathrm{GABA}_{\mathrm{A}}$ and $\mathrm{GABA}_{\mathrm{B}^{\prime}}$, through $\mathrm{Cl}$-influx into the central nervous system. Therefore, damage of GABAergic interneurons will cause continuous unregulated neuronal firing, which will lead to seizures. ${ }^{11}$ However, growing evidence shows that TLE can develop even with minimal neuronal loss. ${ }^{9}$

Mutation of the neuron-specific type $2 \mathrm{~K}^{+} / \mathrm{Cl}^{-}$cotransporter (KCC2) in some of the subicular pyramidal cells, which leads to loss of function, is one of the causes of HS-associated MTLE. ${ }^{12}$ $\mathrm{KCC} 2$ maintains the $\mathrm{Cl}^{-}$homeostasis by active extrusion of $\mathrm{Cl}^{-}$and $\mathrm{K}^{+}$, and mutation of $\mathrm{KCC} 2$ causes accumulation of intracellular $\mathrm{Cl}^{-}$which leads to positive shifts in GABA-mediated currents. ${ }^{13} \mathrm{An}$ increase in intracellular $\mathrm{Cl}^{-}$concentration causes efflux of $\mathrm{Cl}^{-}$through GABA receptors, resulting in depolarisation and hyperexcitability, and subsequently leading to seizures.

Granule cell dispersion (GCD) in the dentate gyrus is observed in HS, which may be a consequence of enhanced proliferation of granule cell precursors as a result of seizures ${ }^{14}$ Dentate granule cells function as a high-resistance gate, which inhibits the propagation of seizures from the entorhinal cortex to the hippocampus in the normal brain. ${ }^{15}$ In TLE, the granule cell stomata are extended from the normal granule-cell layer into the molecular layer to varying extents compared with granule cells in the normal brain, which exhibit a densely packed granule cell layer.16,17 GCD causes changes 
in both the afferent and efferent connections in neurons, which may alter the circuitry of the hippocampal formation. ${ }^{16}$ Axons of granule cells are known as 'mossy fibres' and the hippocampal mossy fibre pathway connects between the granule cells and the pyramidal cells of the CA3 region. ${ }^{18} \mathrm{GCD}$ causes neuroplasticity of granule cell axons into their own dendritic field, a reorganisation process known as mossy fibre sprouting. ${ }^{19}$ This then creates de novo recurrent excitatory circuits, and thus increases excitation that can reduce the threshold for granule cell synchronisation, resulting in epilepsy due to the increase in excitatory signals. 15,19

Malformations of cortical development (MCD) represent abnormalities in the development of the cortex which involves processes such as regionalisation, cell proliferation, neuronal migration and cortical organisation. ${ }^{7}$ Focal cortical dysplasia (FCD) is a subtype of MCD which causes chronic medically refractory epilepsy in the paediatric population, and is a frequent cause of epilepsy in adults. ${ }^{20}$ FCD is classified into three categories: FCD type I, which is cortical dyslamination; FCD type II, which is with the addition of dysmorphic neurons and/or balloon cells, commonly seen in children; and FCD type III, which is associated with another principal lesion such as a tumour or vascular malformation. ${ }^{7,20}$
FCD can cause hyperactivation of the rapamycin (mTOR) pathway, which is involved in regulation of protein and lipid synthesis, cell growth, and metabolism. ${ }^{21}$ The mTOR pathway forms two distinct protein complexes, mTORC1 which is rapamycin-sensitive and promotes protein synthesis by activating downstream signalling cascades, and mTORC2 which acts as a cytoskeletal regulator and is rapamycin-insensitive. ${ }^{22}$ Tuberous sclerosis complex (TSC) is a disorder caused by mutations of mTOR regulatory genes TSC1 or TSC2. Cell overgrowth and synaptogenesis disruptions occur with TSC1 or TSC2 mutations due to abnormal activation of MTORC1, and TSC2 mutation causes hyperexcitability of glutamate-mediated neurons which will lead to seizures. ${ }^{22,23}$

In conclusion, the pathophysiology of TLE is complex and not well-understood; to-date there are several pathological findings in TLE. However, thorough understanding of the mechanism of the disease is crucial in developing new pharmacological therapies. New experimental models, designed by understanding the different defects in TLE are warranted in order to develop new drugs, which are more efficient in managing the condition and improving the quality of life of patients with this form of epilepsy.
1. Stafstrom CE, Carmant L. Seizures and epilepsy: an overview for neuroscientists. Cold Spring Harb Perspect Med. 2015:5:a022426

2. ILAE Commission Report. The epidemiology of the epilepsies: future directions. International League Against Epilepsy. Epilepsia. 1997;38:614-8.

3. Panayiotopoulos CP. Chapter 12 , Symptomatic and Probably Symptomatic Focal Epilepsies: Topographical Symptomatology and Classification. In The Epilepsies: Seizures, Syndromes and Management. Oxfordshire (UK): Bladon Medical Publishing 2005. Available at: www.ncbi.nlm.nih.gov/books/NBK2605/ (accessed 13 January 2020).

4. Berg AT, Berkovic SF, Brodie MJ, et al. Revised terminology and concepts for organization of seizures and epilepsies: report of the ILAE Commission on Classification and Terminolog/ 2005-2009. Epilepsia. 2010;51:676-85.

5. Thom M. Review: Hippocampal sclerosis in epilepsy: a neuropathology review. Neuropathol Appl Neurobiol. neuropathology

6. Téllez-Zenteno JF, Hernández-Ronquillo L. A review of the epidemiology of temporal lobe epilepsy. Epilepsy Res Treat. 2012:630853

7. Al Sufiani F, Ang LC. Neuropathology of temporal lobe epilepsy. Epilepsy Res Treat. 2012;2012:624519.
8. Wieser HG. ILAE Commission on Neurosurgery of Epilepsy. LAE Commission Report. Mesial temporal lobe epilepsy with ILAE Commission Report. Mesial temporal lobe ep

9. Kapur J. Role of neuronal loss in the pathogenesis of recurrent spontaneous seizures. Epilepsy Curr. 2003;3:166-7.

10. Sloviter RS. Decreased hippocampal inhibition and a selective loss of interneurons in experimental epilepsy. Science. 1987;235:73-6

11. Olsen RW, DeLorey TM. GABA Receptor Physiology and Pharmacology. In: Siegel GJ, Agranoff BW, Albers RW, et al., editors. Basic Neurochemistry: Molecular, Cellular and Medical Aspects. 6th edition. Philadelphia: Lippincott-Raven; 1999. Available at: www.ncbi.nIm.nih.gov/books/NBK28090/ (accessed 13 January 2020).

12. Huberfeld $G$, Wittner $L$, Clemenceau S. et al. Perturbed chloride homeostasis and GABAergic signaling in human temporal lobe epilepsy. J Neurosci. 2007;27:9866-73.

13. Sivakumaran S, Cardarelli RA, Maguire J, et al. Selective inhibition of KCC2 leads to hyperexcitability and epileptiform discharges in hippocampal slices and in vivo. I Neurosci. 2015;35:8291-6.

14. Thom M, Martinian L, Williams $G$, et al. Cell proliferation and granule cell dispersion in human hippocampal sclerosis. J Neuropathol Exp Neurol. 2005;64:194-201.
15. Nadler JV. The recurrent mossy fiber pathway of the epileptic brain Neurochem Res. 2003:28:1649-58.

16. Houser CR. Granule cell dispersion in the dentate gyrus of humans with temporal lobe epilepsy. Brain Res. 1990;535:195-204.

17. Freiman TM, Eismann-Schweimler J, Frotscher M. Granule cell dispersion in temporal lobe epilepsy is associated with changes in dendritic orientation and spine distribution. Exp Neurol. 2011;229:332-8

18. Henze DA, Urban NN, Barrionuevo G. The multifarious hippocampal mossy fiber pathway: a review. Neuroscience. 2000;98:407-27

19. Danzer S. Mossy fiber sprouting in the epileptic brain: taking on the Lernaean Hydra. Epilepsy Curr. 2017;17:50-1.

20. Kabat J, Król P. Focal cortical dysplasia - review. Pol J Radiol. 2012;77:35-43.

21. Marsan $E$, Baulac $S$. Review: Mechanistic target of rapamycin (mTOR) pathway, focal cortical dysplasia and epilepsy. Neuropathol Appl Neurobiol. 2018:44:6-17.

22. Marin-Valencia I, Guerrini R, Gleeson JG. Pathogenetic mechanisms of focal cortical dysplasia. Epilepsia. 2014;55:970-8.

23. Griffith JL, Wong M. The mTOR pathway in treatment of epilepsy: a clinical update. Future Neurol. 2018;13:49-58. 